\title{
CRITERIA FOR MULTI AIRPORT SYSTEM DEVELOPMENT IN METROPOLITAN AREA
}

\author{
Surya Apriansyah \\ Program Studi Teknik Dirgantara, Sekolah Tinggi Teknologi Dirgantara \\ apriansyahsurya@gmail.com
}

\begin{abstract}
Soekarno Hatta International Airport and Halim Perdana Kusuma Airport are located in the Jabodetabek metropolitan area which is the largest area for air transportation users in Indonesia. Along with the increasing number of users of air transportation modes, a multiairport system is needed to reduce the burden on one airport. The method used is a qualitative analysis method by comparing existing data with data obtained from research to determine a multi-airport criteria. From the results of data processing, it is concluded that the development of a multi-airport system in the Jabodetabek metropolitan area has several criteria, namely airport distance, accessibility, airport management, airport route services, passenger demand as well as government regulations and policies governing the multi-airport systems.
\end{abstract}

Keywords: Multi Airports, Jabodetabek, Criteria, Regulation

\section{Latar Belakang Masalah}

Indonesia merupakan Negara kepulauan yang terdiri beberapa pulau, untuk menjangkau seluruh wilayah Indonesia dibutuhkan moda transportasi yang efektif dan efisien. Secara umum jenis transportasi terdiri dari transportasi darat, transportasi laut dan transportasi udara. Transportasi udara merupakan salah satu transportasi yang lebih sering digunakan dalam beberapa tahun terakhir untuk menjangkau seluruh wilayah di Indonesia karena lebih efektif dan efisien dalam hal waktu.Seiring dengan perkembangan zaman, area di perkotaan semakin lama semakin jenuh dan bandar udara mengalami kesulitan dalam pengembangan yang berbanding terbalik dengan semakin tingginya lalu lintas penerbangan. Oleh karena itu sistem multi bandar udara dapat menjadi pilihan yang tepat.Sistem multi bandar udara dideskripsikan sebagai sistem bandar udara yang melayani lalu lintas udara pada suatu area metropolitan.[1][2] Sistem multi bandar udara merupakan kumpulan 2 (dua) atau lebih bandar udara yang melayani lalu lintas (udara) komersial dalam suatu kawasan metropolitan. Tren low cost carrier (LCC) di Indonesia menjadi pemicu meningkatnya penumpang yang menggunakan jasa transportasi udara, peningkatan yang sangat pesat ini mewajibkan bandar udara di Indonesia yang khususnya di kawasan metropolitan mengembangkan dan menerapkan sistem multi bandar udara yang terintegrasi dengan baik sehingga setiap rute penerbangan dari dan ke bandar udara semakin berkembang dan maju.Distribusi penumpang yang tidak merata di kawasan metropolitan menyebabkan menumpuknya jumlah penumpang di bandar udara tertentu.[3][4]Bandar udara Internasional Soekarno-Hatta menjadi bandar udara tersibuk nomer satu di Indonesia dengan jumlah penumpang domestic yang datang 24.669.240 penumpang dan berangkat 22.609.240 penumpang pada tahun 2018 dengan 365.414 total penerbangan melalui bandar udara Internasional Soekarno-Hatta. Kelebihan kapasitas di bandar udara dapat mengakibatkan banyak permasalahan di sisi darat maupun di sisi udara bandar udara [5][6] 


\section{Metodologi Penelitian}

Metode yang digunakan dalam penelitian ini adalah metode studi literatur dengan membandingkan sebuah data yang ada dengan data yang didapat dari penelitian untuk menentukan sebuah kriteria multi bandar udara. Objek penelitian yang akan dilakukan penelitian yaitu Bandar udara Internasional Soekarno-Hatta (CGK) dan Bandar udara Internasional Halim Perdanakusuma (HLP) untuk mengetahui kondisi eksisting Bandar udara. Kriteria yang menjadi pertimbangan dalam penentuan sistem multi bandar udara antara lain:

a. Analisis Kondisi Eksisting Bandar Udara

Analisis untuk mengetahui kondisi eksisting dari kedua bandar udara yaitu Bandar udara Internasional Soekarno Hatta dan Bandar udara Internasional Halim Perdanakusuma. Data yang diperoleh yaitu data geografis dan administratif, kapasitas bandar udara, dan alat bantu navigasi bandar udara [7]

b. Analisis Jarak Bandar Udara

Analisis kriteria jarak bandar udara antar bandar udara menggunakan studi literatur yang mengacu pada Peraturan Menteri No.39 Tahun 2019 untuk mengetahui kriteria dalam sistem multi bandar udara [7][8]

c. Analisis Aksesibilitas Bandar Udara

Analisis aksesibilitas antar bandar udara dan akses dari kawasan menuju bandar udara di kawasan. Membandingkan data yang diperoleh dengan berbagai penelitian di dunia. Data yang diperoleh yaitu jarak dan waktu tempuh.

d. Analisis Manajemen Pengelola Bandar Udara

Analisis dengan membandingkan data pada penelitian di dunia dengan kondisi yang ada di Indonesia untuk mengetahui kriteria yang sesuai dalam sistem multi bandar udara [9][10].

e. Analisis Layanan Rute Bandar Udara

Mengetahui layanan rute yang tersedia di kedua bandar udara untuk dijadikan acuan dalam sistem multi bandar udara. Data jadwal dan rute penerbangan yang diperoleh pada tanggal 28 Januari 2020.

f. Analisis Demand Penumpang Bandar Udara

Analisis demand penumpang di bandar udara dengan mengacu dari beberapa penelitian yang ada. Data penumpang eksisting 10 tahun kebelakang (2009-2018) bandar udara Soekarno Hatta dan Bandar udara Halim Perdanakusuma.

g. Analisis Peranan Regulasi dan Kebijakan Pemerintah

Analisis peranan regulasi dan kebijakan pemerinah dalam sistem multi bandar udara ditinjau dari beberapa aspek dalam mendukung terciptanya sistem multi bandar udara di kawasan Jabodetabek.

\section{Hasil dan Pembahasan}

a. Kriteria Multi Bandar Udara

Multi Bandar udara memiliki parameter yang dijadikan kriteria dalam pengembangan sistem multi Bandar udara. Berikut ini merupakan parameter yang dapat dijadikan kriteria dalam pengembangan sistem multi bandar udara, yaitu:

- Jarak Bandar Udara

Salah satu parameter yang dapat dijadikan dalam kriteria yaitu jarak antar bandara. Jarak antar bandar udara yang ada di dunia seperti pada tabel 1 . 
Tabel 1. Jarak Antar Bandar Udara Yang Ada di Dunia

\begin{tabular}{|c|c|c|c|}
\hline \multicolumn{2}{|c|}{ Wilayah Metropolitan } & Bandar Udara & Jarak Antar Bandar Udara \\
\hline \multirow{2}{*}{ Asia Pasific } & \multirow{2}{*}{ Tokyo } & Haneda & \multirow{2}{*}{59} \\
\hline & & Narita & \\
\hline \multirow{5}{*}{ Europe } & \multirow{5}{*}{ London } & Heathrow & \multirow{5}{*}{51} \\
\hline & & Gatwick & \\
\hline & & Stansted & \\
\hline & & Luton & \\
\hline & & City & \\
\hline \multirow{2}{*}{ Latin America } & \multirow{2}{*}{ Belo Horizonte } & Neves & \multirow{2}{*}{25} \\
\hline & & Pampulha & \\
\hline \multirow{2}{*}{ Middle East } & \multirow{2}{*}{ Tel Aviv } & Ben Gurion & \multirow{2}{*}{15} \\
\hline & & Sde Dov & \\
\hline \multirow{4}{*}{ North America } & \multirow{4}{*}{ New York } & Kennedy & \multirow{4}{*}{47} \\
\hline & & Newark & \\
\hline & & LaGuardia & \\
\hline & & Islip & \\
\hline
\end{tabular}

Dari kelima wilayah Metropolitan diatas memeiliki jarak antar bandar udara ratarata sekitar 39,4 Km. Menurut PM No.39 Tahun 2019 tentang Tatanan Kebandarudaraan Nasional. Radius pelayanan di pulau Jawa yaitu $50 \mathrm{~km}$ (jarak lurus 2 bandar udara $100 \mathrm{~km}$ ) atau waktu tempuh moda transportasi minimal 4 jam. Radius pelayanan tersebut berlaku jika dua bandara tersebut beroperasi masing-masing dan tidak menerapkan sistem multi bandar udara.

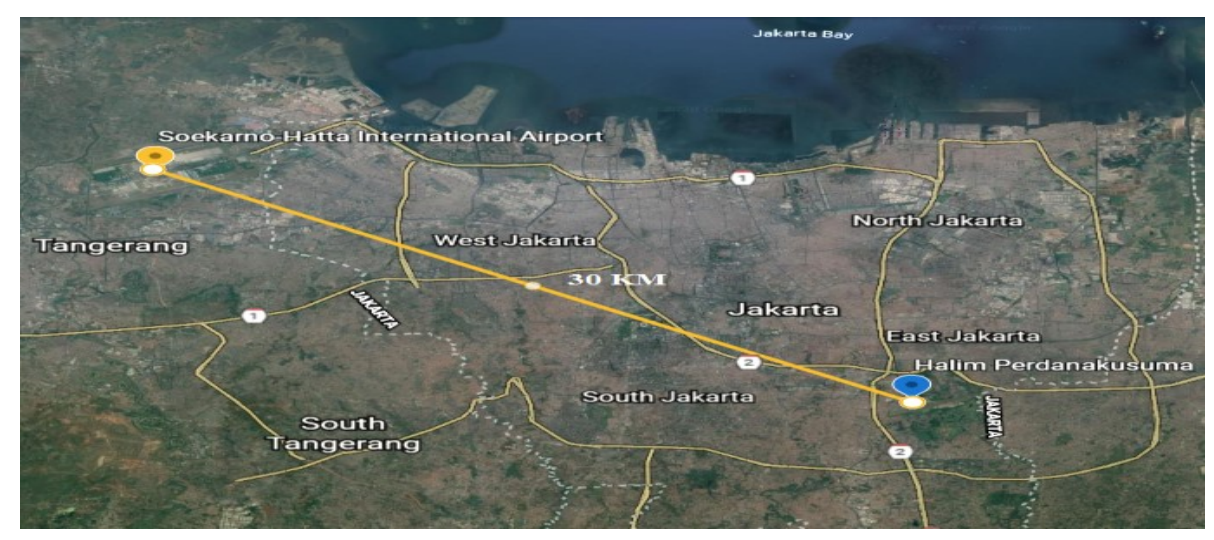

Gambar 1. Jarak Bandar Udara Soekarno Hatta dan Halim Perdanaksuma

Di kawasan Metropolitan Jabodetabek, Bandar udara Soekarno Hatta dan Bandar udara Halim Perdanakusuma memiliki jarak lurus antar 2 bandar udara $30 \mathrm{Km}$, hal ini dapat dikatakan memenuhi dalam kriteria multi bandar udara karena jarak dari kedua bandar udara kurang dari $100 \mathrm{Km}$. Hal ini memungkinkan untuk diberlakukannya sistem multi bandar udara yang saling berbagi penumpang di kawasan tersebut (market share). 
- Aksesibilitas

Akses antar bandar udara dan akses dari kawasan menuju bandar udara di Kawasan Metropolitan Jabodetabek sangat mudah, moda transportasi yang bisa digunakan antara lain Bus, Kereta, Taksi bandara, Taksi daring, Kendaraan pribadi.

Tabel 2. Jarak dan Waktu Tempuh Antar Bandar Udara

\begin{tabular}{|c|c|c|c|}
\hline \multirow{2}{*}{} & \multicolumn{3}{|c|}{ Bandar Udara Soekarno Hatta } \\
\cline { 2 - 4 } & \multicolumn{2}{|c|}{ Mobil } & Kereta \\
\cline { 2 - 4 } & $\begin{array}{c}\text { Jarak } \\
(\mathrm{Km})\end{array}$ & $\begin{array}{c}\text { Waktu } \\
\text { (Menit) }\end{array}$ & $\begin{array}{c}\text { Waktu } \\
\text { (Menit) }\end{array}$ \\
\hline $\begin{array}{c}\text { Bandar Udara Halim } \\
\text { Perdanakusuma }\end{array}$ & 37,6 & 28 & 116 \\
\hline
\end{tabular}

Dari tabel 2 diketahui bahwa jarak terdekat antara 2 bandar udara adalah 37,6 Km dengan waktu yang ditempuh sekitar 28 menit jika menggunakan mobil pribadi ataupun taksi melalui jalan tol, apabila menggunakan kereta Bandara waktu yang dibutuhkan sekitar 116 menit, hal tersebut dikarenakan jika menggunakan kereta api harus melakukan transit di beberapa stasiun sebelum sampai di stasiun terdekat.

Sebagai perbandingan berikut ini merupakan jarak dari pusat kota ke bandar udara di sebuah kawasan metropolitan yang ada di dunia seperti pada tabel 3.3.

Tabel 3. Jarak Dari Pusat Kota Bandar Udara Yang Ada di Dunia

\begin{tabular}{|c|c|c|c|}
\hline \multicolumn{2}{|c|}{ Wilayah Metropolitan } & Bandar Udara & $\begin{array}{c}\text { Jarak Dari } \\
\text { Pusat Kota }(\mathrm{Km})\end{array}$ \\
\hline \multirow{2}{*}{ Asia Pasific } & \multirow{2}{*}{ Tokyo } & Haneda & 12,87 \\
\hline & & Narita & 51,49 \\
\hline \multirow{5}{*}{ Europe } & \multirow{5}{*}{ London } & Heathrow & 22,53 \\
\hline & & Gatwick & 40,23 \\
\hline & & Stansted & 48,27 \\
\hline & & Luton & 43,44 \\
\hline & & City & 11,26 \\
\hline \multirow{2}{*}{ Latin America } & \multirow{2}{*}{ Belo Horizonte } & Neves & 27,35 \\
\hline & & Pampulha & 4,83 \\
\hline \multirow{2}{*}{ Middle East } & \multirow{2}{*}{ Tel Aviv } & Ben Gurion & 11,26 \\
\hline & & Sde Dov & 6,44 \\
\hline \multirow{4}{*}{ North America } & \multirow{4}{*}{ New York } & Kennedy & 20,92 \\
\hline & & Newark & 14,48 \\
\hline & & LaGuardia & 11,26 \\
\hline & & Islip & 77,23 \\
\hline
\end{tabular}

Dari Tabel 3.3 diatas diketahui bahwa jarak dari pusat kota ke bandar udara memiliki rata-rata jarak yaitu $26,92 \mathrm{Km}$ dengan jarak terpanjang yaitu 77,23 Km pada Bandar udara Islip di New York dan jarak terpendek yaitu 4,83 Km pada Bandar udara 
pampulha di Belo Horizonte. Di kawasan Metropolitan Jabodetabek memiliki jarak dan waktu tempuh sebagai berikut:

Tabel 4. Jarak dan Waktu Tempuh Dari Pusat Kota

\begin{tabular}{|c|c|c|c|c|}
\hline \multirow{2}{*}{ Bandar Udara } & \multicolumn{4}{|c|}{ Jarak Dari Pusat Kota } \\
\cline { 2 - 5 } & Jarak & \multicolumn{2}{|c|}{ Mobil } & Kereta \\
\cline { 2 - 5 } & Lurus & Jarak & $\begin{array}{c}\text { Waktu } \\
\text { (Mm) }\end{array}$ & $\begin{array}{c}\text { Waktu } \\
\text { (Menit) }\end{array}$ \\
(Menit)
\end{tabular}

Dari Tabel 4 diketahui Bandar udara Soekarno Hatta memiliki jarak $20 \mathrm{Km}$ dari pusat kota dan Bandar udara Halim Perdanakusuma 11,8 Km dari pusat kota. Jarak tersebut sesuai dengan kriteria dalam multi bandar udara yang memiliki rata-rata jarak dari pusat kota yaitu $26,92 \mathrm{Km}$.

- Manajemen Pengelola Bandar Udara

Berdasarkan data pada penelitian Bonnefoy (2008) manajemen pengelola bandar udara mayoritas dimiliki satu instansi atau pengeola bandar udara yang sama, hal ini mempermudah dalam pengoperasian dan perencanaan infrastruktur untuk menunjang multi bandar udara. Pengembangan multi bandar udara akan lebih mudah jika dikelola oleh satu pengelola yang sama. Berikut ini merupakan manajemen pengelola bandar udara yang ada di dunia pada tabel 5 .

Tabel 5. Manajemen Pengelola Bandar Udara Yang Ada di Dunia

\begin{tabular}{|c|c|c|}
\hline Wilayah Metropolitan & Bandar Udara & Manajemen Pengelola \\
\hline \multirow{4}{*}{ Tokyo } & Haneda & $\begin{array}{c}\text { Tokyo Aviation Bureau, Ministry of } \\
\text { Land, Infrastructure and } \\
\text { Transport }\end{array}$ \\
\cline { 2 - 3 } & Narita & $\begin{array}{c}\text { Narita International } \\
\text { Airport }\end{array}$ \\
\hline \multirow{5}{*}{ London } & Heathrow & BAA Limited \\
\cline { 2 - 3 } & Gatwick & BAA Limited \\
\cline { 2 - 3 } & Stansted & BAA Limited \\
\cline { 2 - 3 } & Luton & $\begin{array}{c}\text { ACDL - London Luton } \\
\text { Airport Operation } \\
\text { Ltd }\end{array}$ \\
\cline { 2 - 3 } & City & $\begin{array}{c}\text { AIG, GE Capital \& } \\
\text { Credit Suisse }\end{array}$ \\
\hline \multirow{2}{*}{ Belo Horizonte } & Neves & Infraero \\
\cline { 2 - 3 } & Pampulha & Infraero \\
\hline \multirow{2}{*}{ Tel Aviv } & Ben Gurion & Israel Airports Authority \\
\cline { 2 - 3 } & Sde Dov & Israel Airports Authority \\
\hline \multirow{5}{*}{ New York } & Kennedy & $\begin{array}{c}\text { Port Authority of New York } \\
\text { and New Jersey }\end{array}$ \\
\cline { 2 - 3 } & Newark & $\begin{array}{c}\text { Port Authority of New York } \\
\text { and New Jersey }\end{array}$ \\
\cline { 2 - 3 } & LaGuardia & Port Authority of New York \\
\cline { 2 - 3 } & &
\end{tabular}




\begin{tabular}{|l|c|c|}
\hline Wilayah Metropolitan & Bandar Udara & Manajemen Pengelola \\
\hline & & and New Jersey \\
\cline { 2 - 3 } & Islip & Town of Islip \\
\hline
\end{tabular}

Pada Tabel 5 diatas dapat diketahui bahwa sebagian besar manajemen pengelolaan bandar udara dikelola oleh satu instansi yang sama hal tersebut mempermudah dalam pengoperasian dan perencanaan infrastruktur untuk menunjang multi bandar udara. Bandar udara Soekarno Hatta dan Bandar udara Halim Perdanakusuma keduanya dikelola oleh PT Angkasa Pura II (Persero), hal ini memenuhi kriteria dalam pengembangan sistem multi bandar udara.

- Layanan Rute Bandar Udara

Bandar Udara Internasional Soekarno Hatta melayani berbagai rute penerbangan domestik maupun internasional. Layanan transportasi udara tersebut melibatkan beberapa maskapai. Berikut ini merupakan rute penerbangan di Bandar Udara Internasional Soekarno Hatta pada tabel 6.

Tabel 3. 6 Rute Penerbangan Bandar Udara Soekarno Hatta

\begin{tabular}{|c|c|c|}
\hline Jadwal & Flight Number & Kedatangan \\
\hline $12: 05$ & GA 0581 & AAP \\
\hline $9: 10$ & ID 6171 & Ambon \\
\hline 9:00 & QG 0663 & Bali \\
\hline $7: 25$ & ID 6251 & Balikpapan \\
\hline $12: 20$ & QG 2256X & Bandar Lampung \\
\hline $8: 15$ & ID 8863 & Batam \\
\hline $7: 15$ & JT 0631 & Bengkulu \\
\hline $12: 35$ & GA 0127 & Jambi \\
\hline $11: 00$ & QG 0913 & Kualanamu \\
\hline $9: 20$ & ID 6541 & Kupang \\
\hline $12: 25$ & ID 6265 & Makassar \\
\hline $9: 55$ & JT 0813 & Malang \\
\hline $12: 25$ & JT 0353 & Padang \\
\hline $11: 50$ & JT 0333 & Palembang \\
\hline $10: 40$ & GA 0435 & Praya \\
\hline $7: 00$ & QG 0803 & Semarang \\
\hline $11: 00$ & QG 0881 & Silangit \\
\hline $7: 35$ & ID 6597 & Surabaya \\
\hline $12: 20$ & GA 0225 & Surakarta \\
\hline $11: 40$ & JT 0121 & Tanjung Pandan \\
\hline $7: 20$ & ID 6371 & YIA \\
\hline $6: 30$ & QG 0771 & Yogyakarta \\
\hline
\end{tabular}

Pada Bandar Udara Internasional Halim Perdanakusuma melayani berbagai rute penerbangan domestik maupun internasional. Layanan transportasi udara tersebut melibatkan beberapa maskapai. Berikut ini merupakan rute penerbangan di Bandar Udara Internasional Halim Perdanakusuma Tabel 7. 
Tabel 7. Rute Penerbangan Bandar Udara Halim Perdanakusuma

\begin{tabular}{|c|c|c|}
\hline Jadwal & Flight Number & Kedatangan \\
\hline $12: 40$ & ID 7280 & AAP \\
\hline $13: 55$ & ID 7770 & Ambon \\
\hline $8: 10$ & QG 0193 & Bali \\
\hline $7: 30$ & ID 7204 & Balikpapan \\
\hline $14: 55$ & QG 1972 & Bandar Lampung \\
\hline $19: 05$ & ID 7082 & Batam \\
\hline $19: 00$ & ID 7128 & Bengkulu \\
\hline $11: 20$ & QG 191 & Jambi \\
\hline $10: 10$ & QG 9021 & Kualanamu \\
\hline $15: 20$ & ID 7348 & Kupang \\
\hline $14: 50$ & ID 7708 & Makassar \\
\hline $10: 50$ & QG 0161 & Malang \\
\hline $14: 25$ & ID 7106 & Padang \\
\hline $12: 05$ & ID 7042 & Palembang \\
\hline $11: 00$ & QG 0199 & Praya \\
\hline $7: 55$ & QG 0141 & Semarang \\
\hline $11: 20$ & QG 2011 & Silangit \\
\hline $8: 55$ & ID 7510 & Surabaya \\
\hline $12: 55$ & QG 0123 & Surakarta \\
\hline $16: 50$ & QG 0075 & Tanjung Pandan \\
\hline $14: 20$ & QG 0133 & YIA \\
\hline 7:00 & QG 0111 & Yogyakarta \\
\hline
\end{tabular}

Dari Tabel 3.6 dan Tabel 3.7 diatas bandar udara Soekarno Hatta dan Halim Perdanakusuma melayani 22 rute yang sama, maka dari itu sistem multi bandar udara sangat diperlukan untuk membagi market share dari Kawasan Metropolitan Jabodetabek untuk mengurangi penumpukan di salah satu bandar udara. Pembagian peran bandar udara dapat direalisasikan jika memiliki pelayanan penerbangan yang sama, misalnya salah satu bandar udara khusus melayani low cost carrier.

- Demand Penumpang

Demand Penumpang pada Bandar udara Soekarno Hatta dan Bandar udara Halim Perdanakusuma tiap tahunnya selalu mengalami kenaikan, bertambahnya demand penumpang di kawasan Metropolitan Jabodetabek menjadi faktor yang dapat dijadikan harus dikembangannya sistem multi bandar udara di Kawasan Jabodetabek. Berikut ini merupakan penumpang pada Bandar udara Soekarno Hatta dan Bandar udara Halim Perdanakusuma, antara lain pada tabel 8 dan tabel 9. 
Tabel 8. Penumpang Bandar Udara Soekarno Hatta

\begin{tabular}{|c|c|c|c|}
\hline \multicolumn{3}{|c|}{ Penumpang } \\
\hline Tahun & Kedatangan & Keberangkatan & Jumlah \\
\hline 2009 & 14445568 & 13319140 & 27764708 \\
\hline 2010 & 16905286 & 15430749 & 32336035 \\
\hline 2011 & 19835957 & 17592899 & 37428856 \\
\hline 2012 & 24498236 & 21425520 & 45923756 \\
\hline 2013 & 23578314 & 20574428 & 44152742 \\
\hline 2014 & 21951895 & 20028714 & 41980609 \\
\hline 2015 & 20802860 & 19151202 & 39954062 \\
\hline 2016 & 22111745 & 20492917 & 42604662 \\
\hline 2017 & 23621723 & 21931574 & 45553297 \\
\hline 2018 & 24669240 & 22609828 & 47279068 \\
\hline
\end{tabular}

Tabel 9. Penumpang Bandar Udara Halim Perdanakusuma

\begin{tabular}{|c|c|c|c|}
\hline \multicolumn{3}{|c|}{ Penumpang } \\
\hline Tahun & Kedatangan & Keberangkatan & Jumlah \\
\hline 2009 & 90520 & 103701 & 194221 \\
\hline 2010 & 79209 & 84864 & 164073 \\
\hline 2011 & 79601 & 85347 & 164948 \\
\hline 2012 & 90691 & 62937 & 153628 \\
\hline 2013 & 101795 & 93404 & 195199 \\
\hline 2014 & 775334 & 767492 & 1542826 \\
\hline 2015 & 1473207 & 1482125 & 2955332 \\
\hline 2016 & 2807480 & 2780951 & 5588431 \\
\hline 2017 & 3433623 & 3309394 & 6743017 \\
\hline 2018 & 3712096 & 3570097 & 7282193 \\
\hline
\end{tabular}

Dari kedua tabel diatas pada tahun 2018 di Bandar udara Soekarno Hatta memiliki 47.279.068 penumpang pertahun, sedangkan di Bandar udara Halim Perdanakusuma memiliki 7.282.193 penumpang pertahun. Berdasarkan pada jurnal penelitian Loo, B.P. (2008) suatu kawasan dapat memenuhi kriteria dalam sistem multi bandar udara jika bandar udara di kawasan tersebut melayani 10 juta penumpang tiap tahunnya, dari kriteria tersebut dapat dikatakan bahwa Bandar udara Soekarno Hatta dan Halim Perdanakuma memenuhi syarat dari sistem multi bandar udara.

Menurut Bonnefoy (2010) bandar udara primer adalah bandar udara yang melayani lebih dari $20 \%$ penumpang pada suatu kawasan dan bandar udara sekunder yang melayani kurang dari 20\% penumpang atau lebih dari 500.000 tiap tahunnya. Bandar udara Soekarno Hatta menjadi Bandar udara primer karena melayani sekitar $87 \%$ total penumpang dan Bandar udara Halim Perdanakusuma menjadi bandar udara sekunder karena melayani sekitar $13 \%$ total penumpang yang ada di Kawasan Metropolitan Jabodetabek. 


\section{b. Peranan Regulasi dan Kebijakan Pemerintah}

Peran pemerintah dalam pengembangan sistem multi bandar udara dapat dilihat dalam sudut pandang perencanaan infrastruktur. Perencanaan infrastruktur dalam suatu kawasan berfungsi sebagai pendukung dalam tercapainya sistem multi bandar udara. Pada Tabel 3.10 merupakan regulasi dan dasar hukum yang mengatur dalam penerapan multi bandar udara, antara lain:

Tabel 10. Regulasi dan Dasar Hukum

\begin{tabular}{|l|l|}
\hline No & \multicolumn{1}{|c|}{ Regulasi dan Dasar Hukum } \\
\hline 1 & Undang - Undang No.1 Tahun 2009 Tentang Penerbangan \\
\hline 2 & $\begin{array}{l}\text { Peraturan Pemerintah No.13 Tahun 2017 Tentang Rencana Tata Ruang Wilayah } \\
\text { Nasional }\end{array}$ \\
\hline 3 & $\begin{array}{l}\text { Peraturan Menteri Perhubungan PM No.39 Tahun 2019 Tentang Tatanan } \\
\text { Kebandarudaraan Nasional }\end{array}$ \\
\hline 4 & $\begin{array}{l}\text { Peraturan Menteri Perhubungan KM 48 Tahun 2008 Tentang Rencana Induk } \\
\text { Bandar Udara Soekarno-Hatta }\end{array}$ \\
\hline 5 & $\begin{array}{l}\text { KP No.012 Tahun 2018 Tentang Reviu Rencana Strategis (RENSTRA) Direktorat } \\
\text { Jenderal Peerhubungan Udara Tahun 2015-2019 }\end{array}$ \\
\hline
\end{tabular}

- Rencana induk

Rencana induk bandar udara berfungsi sebagai pedoman pembangunan dan pengembangan bandar udara yang mencakup seluruh kebutuhan dan penggunaan serta tata letak ruang udara untuk kegiatan penerbangan dan kegiatan penunjang penerbangan dengan mempertimbangkan aspek - aspek teknis, keamanan dan aspek terkait lainnya. Rencana induk bandar udara Soekarno Hatta yang diatur dalam Peraturan Menteri Perhubungan KM 48 Tahun 2008 yang mengatur tentang perencanaan infrastruktur penunjang dan pengembangan bandar udara, contohnya ketentuan maksimal penumpang dan penerbangan.

- Dasar hukum

Undang - Undang No.1 Tahun 2009 Tentang Penerbangan (p. 55) dan PP No.13 Tahun 2017 Tentang Rencana Tata Ruang Wilayah Nasional (pp. 18-19) mengklasifikasikan jenis bandar udara menjadi bandar udara primer, sekunder sesuai dengan skala pelayanan bandara. Peraturan Menteri Perhubungan PM No.39 Tahun 2019 dan KP 012 Tahun 2018 Tentang Reviu Rencana Strategis (RENSTRA) Direktorat Jenderal Perhubungan Udara Tahun 2015-2019 (pp. IV-29) yang menyatakan bahwa pada bandar udara pengumpul primer dengan cakupan wilayah tertentu yang telah mencapai kapasitas maksimal dan tidak terdapat kemungkinan untuk dikembangkan lagi, dilakukan kajian untuk mengembangkan konsep sistem multi bandar udara.

\section{Kesimpulan}

Dari hasil penelitian diatas dapat disimpulkan bahwa sistem multi bandar udara di Kawasan Metropolitan Jabodetabek memiliki beberapa kriteria antara lain jarak bandar udara, aksesibilitas, manajemen pengelola bandar udara, layanan rute bandar udara, dan demand penumpang sudah memenuhi kriteria dalam pengembangan sistem multi bandar udara.

Peranan regulasi dan kebijakan pemeritah dalam pengembangan multi bandar udara dapat diliat dari sudut pandang perencanaan infrastuktur. Perencanaan infrastruktur meliputi rencana induk kawasan dan rencana induk bandar udara di kawasan Metropolitan Jabodetabek. 


\section{DAFTAR PUSTAKA}

[1] Attaalla, Farouk Abdelnabi Hassanein. 2019. Multi-Airport Systems As A Tourism Phenomenon: A Critical Review And A New Concept. Egypt: Fayoum University.

[2] Bonnefoy Philippe A., dan John Hansman. 2008. Scalability of The Air Transportation System and Development of Multi-Airport Systems: A Worldwide Perspective. USA: Massachusetts Institute of Technology.

[3] Bonnefoy Philippe A., Richard D. N., dan John Hansman. 2010. Evolution and Development of Multiairport Systems: Worldwide Perspective.

[4] Defiani, Amalia. 2015. Sistem Multi-Bandara Di Indonesia: Tinjauan Dari Sudut Pandang Kebijakan (Studi Kasus: Bandar Udara Soekarno Hatta Dan Bandar Udara Baru Karawang). Jakarta: Direktorat Bandar Udara.

[5] De Neufville, Richard dan Amedeo R. O. 2013. Airport Systems Planning, Design, and Management. New York: McGraw-Hill.

[6] Hansen, M. Dan Weidner, T. 1995. Multiple airport systems in the United States: current status and future prospects.

[7] Kasarda, J. D. 2008. A Study of Multiple Airport Metropolitan Regions Worldwide: Implication for AITN and Belo Horizonte. USA: University of North Carolina.

[8] Loo, B.P. 2008. Passengers Airport Choice Within Multi-Airport Regions (MARs): Some Insight From a Stated Preference Survey at Hong Kong International Airport. Journal of Transport.

[9] Mangatu, Syam Dev. 2014. One City, Six Airports. Heathrow, Gatwick, Stansted, Luton, London City and Southend.

[10] Pasaribu, Hisar M. 2012. Sistem Transportasi Udara, Diktat Kuliah, Bandung: Departemen Teknik Penerbangan Intitut Teknologi Bandung. 